\title{
9. Rivers of Memory and Forgetting
}

JOHN R. WAGNER

\section{Introduction}

Kamu Yali ${ }^{1}$ is a water world. Average rainfall is about $5,000 \mathrm{~mm}$ per year and daily showers are common even during the dry season that lasts from November to April. The village is located along the shoreline of Nasau Bay in Papua New Guinea (PNG) and its territory extends as far out into the Solomon Sea as village men can safely travel in outrigger canoes. Village houses are built facing the sea, several feet off the ground, in order to avoid wet season floods; local transportation systems are water-based since there are no roads in this part of PNG; outrigger canoes and motorised boats line the beach in front of the houses; villagers go to sleep listening to the pounding of the surf. Inland, behind the village to the southwest, lies a mountain ridge known in the local Kala language as Batatalã ('Blue Mountain'). ${ }^{2}$ Batatalã is home to a craggy, inhospitable moss-cloud

1 The official name of the village is Lababia but in 2002 villagers requested that I refer to it as Kamu Yali in my publications. In their language (Kala), Kamu Yali is the name of one of the hamlets near the centre of the current village site, and is considered by them to be the correct name for the village. They first began using this name in 1996 when they partnered with Village Development Trust (VDT), a local non-governmental organisation, to create a conservation and development project. VDT staff incorrectly wrote the name as Kamiali, however, and this name is still in use today by many people, especially those who first came to know the village through the Kamiali Conservation and Development Project.

2 The spelling of Batatalã and of other local names and words is based on the Kala orthography developed by Schreyer and Wagner (2013) in partnership with the Kala Language Committee. The diacritic that appears above the final letter 'a' indicates a nasal vowel. The letter ' $\mathrm{l}$ ' is used to indicate an alveolar lateral flap. 
forest that blocks the movement of people between high-elevation inland valleys and coastal regions; the headwaters of the four rivers that dominate Kamu Yali territory all arise on the eastern, seaward side of this ridge (see Figure 9.1).

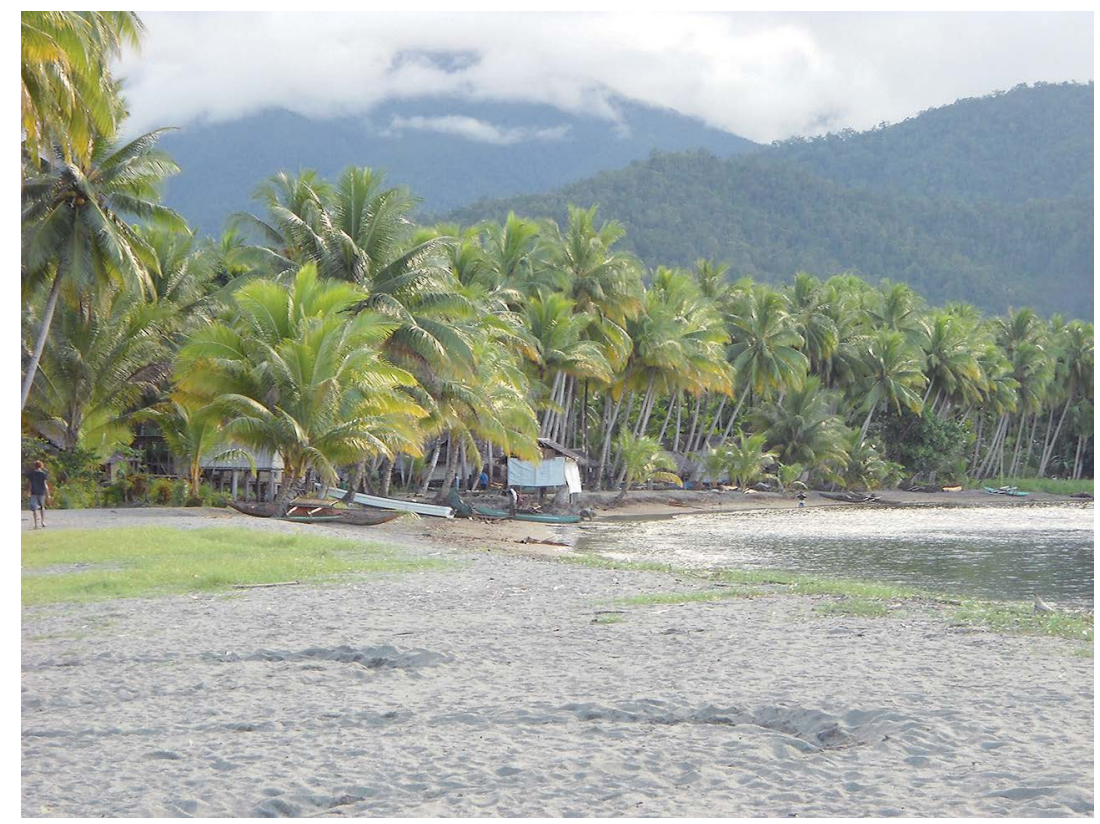

Figure 9.1 Village shoreline dotted with canoes, with Blue Mountain foothills shrouded in clouds.

Source: Photo by the author.

Although Kamu Yali residents, like all Kala people, identify themselves as coastal people (pipol bilong solwara in Tok Pisin $^{3}$ ) and are careful to distinguish themselves from 'bush' or inland people (pipol bilong bus), I focus in this chapter on the importance of rivers to Kamu Yali social life and cultural identity. Villagers' reliance on rivers is sufficient for them to be described as a river people, though this is not a claim I have ever heard them make, not even those of them who locate their gardens several kilometres inland from the sea along the Bitoi River. Only a very few villagers are familiar with the upper reaches of any of the rivers, and inland travel beyond gardening areas is infrequent and mainly limited to

3 Tok Pisin, generally referred to as Melanesian Pidgin in English, serves as a lingua franca throughout the country. Having become a relatively fluent speaker during the full year I spent in Kamu Yali in 1998-99, it is the language I normally use when in the village. 
hunting and the gathering of wild foods, fuelwood and building materials. My focus on Kamu Yali rivers allows me, nevertheless, to demonstrate that coastal people can simultaneously be river people, and that the opposition between salt water and fresh water, though deeply embedded in the cosmology and discourse of many Pacific island peoples (see Hviding, this volume), is historically and geographically contingent rather than universal. It is the combination of agricultural land with riparian and marine resources that makes life viable in this part of the country, and Kamu Yali history and identity are rooted equally in these three domains.

My foregrounding of rivers and riverine resources also allows me to emphasise the agency of rivers within the social lives of Kamu Yali villagers. As noted in the introduction to this volume, scholars from many disciplinary backgrounds now attribute agency to a wide variety of non-human 'actors', a trend that stands in sharp opposition to the more common historical tendency to define agency as an exclusively human characteristic dependent on conscious intent. Social scientists in the field of science and technology studies have been especially prominent among those who apply the term to a wide range of 'actants' (Latour 2005), but they are joined by many others, including ethnographers (Viveiros de Castro 1998; Descola 2013), philosophers (Barad 2003; Bennett 2010; Morton 2013) and archaeologists (Hodder 2012; Malafouris and Renfrew 2013; Edgeworth 2014) who seek to challenge existing ideas about materiality itself as well as the relationship of ecology to culture. It is not my intent here to endorse any particular line of argument on this issue or to present empirical evidence in support of the idea that rivers do, in fact, possess agency. I use the term simply because it helps bridge the gap between social and ecological domains.

There can, then, be no radical break between social and ecological relations; rather, the former constitute a subset of the latter. What this suggests is the possibility of a new kind of ecological anthropology, one that would take as its starting point the active, perceptual engagement of human beings with the constituents of their world-for it is only from a position of such engagement that they can launch their imaginative speculations concerning what the world is like. (Ingold 2000: 60)

The approach Ingold proposes is also one that constructs an understanding of things based on 'their position within a relational field' rather than on the mere unfolding of internal characteristics (ibid.: 97). Ingram (2010) proposes a relational definition of agency on the basis of his study of human/microbial relations. Following Barard (2003), he proposes that we 
'should move away from a focus on the non-human as a separate, ethically and agentially equivalent subject and ... focus on the activity that results through relationships and interaction' (Ingram 2010: 102). This is the approach I follow in this chapter as I describe the relationship of Kamu Yali villagers to their four rivers.

More fundamentally, framing my account of Kamu Yali around the rivers also allows me to analyse and interpret historical and contemporary patterns of change as the consequence of selective processes of memory and forgetting. As Harrison (2004) points out in his account of the Manambu village of Avatip, located on the Sepik River in PNG, river features can act as mnemonic devices, playing important roles in the way individual and collective memories are organised and retained. In Kamu Yali, each river is strongly associated with a particular kinship group in the village and is the site of historical events that have shaped the history of the community in distinct ways. Stories about the rivers are thus simultaneously stories about pivotal moments in village history and about the coming into being of the kin groups that continue to structure village life in fundamental ways. But Harrison (2004: 149) also notes that both remembering and forgetting can occur as expressions of power, not just as innocent or random occurrences. This insight also has traction at Kamu Yali, where the mouths of the Alewili and Saia rivers are the sites of proposed chromium mines, and villagers have been asked to identify the respective 'landowners' as part of the approval process for obtaining a mining licence. This process requires that villagers remember and re-engage with ancestral knowledge about the site, but, at the same time, pressures them to renounce and forget that knowledge so that the mining company can transform a place inhabited by ancestor spirits into a zone of industrial exploitation.

\section{The Rivers}

Although I was intensely conscious of living in a water world during the period of my doctoral research in Kamu Yali in 1998-99, rivers were by no means the primary focus of my research. I had come to Kamu Yali to study community-based resource management practices, and my main focus was on land and sea tenure, gardening and fishing practices, and the sustainable development projects that were being implemented in the village as part of the Kamiali Conservation and Development Project 
(Wagner 2002, 2005). The other most prominent 'resource' on which I concentrated was Batatalã ('Blue Mountain'). Village Development Trust (VDT), the non-governmental organisation managing the project, had begun to emphasise the unusual ecological features of this high-elevation forest in their funding applications, and had facilitated its inclusion in a newly established wildlife management area (Bein 1998; Wagner 1999).

I nevertheless learned a great deal about Kamu Yali rivers though my study of land tenure, since rivers sometimes served as boundary markers, and through my study of agriculture, since the ecological characteristics of rivers largely determined the location of swidden gardens. I also noted many of the other ecological services they provided, such as habitat for wild food species, most notably sago palm. More by chance than by design, I recorded a number of stories about the relationships of rivers to various kin groups in the village. I came to know Kamu Yali rivers most intimately, however, through my own direct and unavoidable physical experiences of them, since foot travel throughout the village territory requires their constant fording. I had to develop strategies that allowed me to cross rivers safely while carrying notebooks, a camera, survey and GPS equipment and, perhaps, a change of clothing depending on the weather and time of year. Travel to distant gardens, or to forested or swampy areas, also required sturdy boots that had to be laboriously unlaced and re-laced for each crossing. The ideal trousers and shirts were ones made from materials that would dry quickly. During the dry season, when the rivers were no more than waist high and only $10 \mathrm{~m}$ across, the risks were low, the inconvenience was minimal and they were compensated by the pleasure of a cool swim on a hot day. There was no compensation during wet season, however, which lasted from May until September. Currents could be very strong and the water could be shoulder high or over our heads in the deepest channels. Under those conditions, we had to cross the rivers diagonally, moving downstream with the flow of water, slowly edging towards the other bank while holding our equipment above our heads. The meandering courses of the rivers also meant that we often had to cross the same river several times during a single trip if we were travelling inland away from the mouth of a river. Crossings that were easy for my village companions were always much more difficult for me, and although I had very few spills in the course of a year, these crossings were among my least favourite village experiences. 


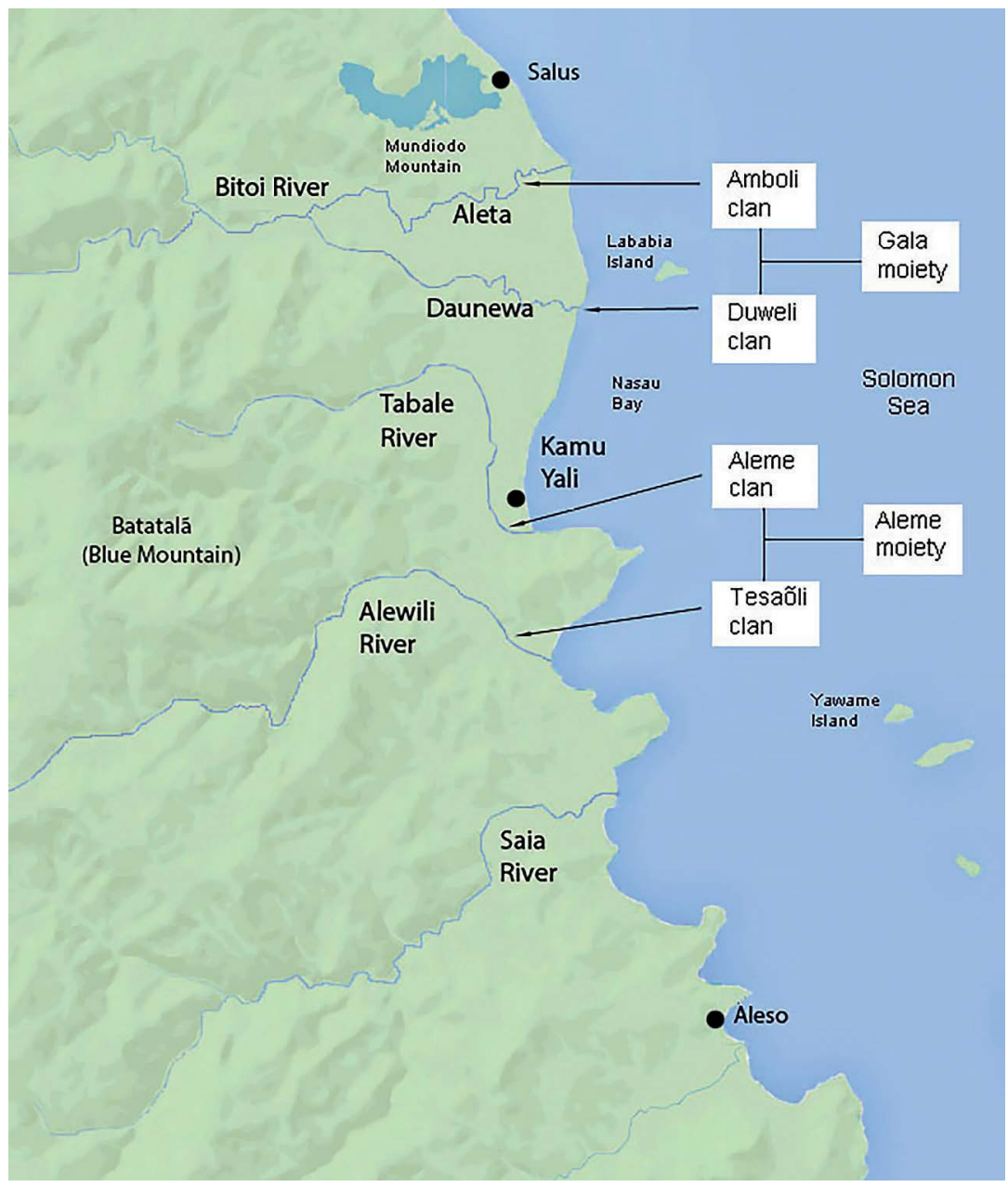

Figure 9.2 Kamu Yali rivers and associated kin groups.

Source: Map by the author.

Of the four main rivers that drain the steep flanks of Blue Mountain, the Bitoi River ${ }^{4}$ in the north carries the largest volume of water. As it descends from headwaters that arise at elevations of over $2,000 \mathrm{~m}$, it is joined by

4 The origin of the term Bitoi is uncertain, but dates back to the early 1900s when German colonial officials began assigning names to village sites and local geographical features. Maps of the area still display German names for some features, such as Nasau Bay and Hessen Bay, while other features have names that are neither German nor Kala in origin. A few knowledgeable villagers suggested to me that the official name for the village, Lababia, arose as the result of a misunderstanding by German officials of the local Kala name for the village site they occupied at the time of contact. There is no consensus, however, over the origins of either of the names Lababia or Bitoi. 
other streams and by the equally large Buyawim River at an elevation of about $600 \mathrm{~m}$ (see Figure 9.2). Shortly after its confluence with the Buyawim, it divides into two distinct channels at the western, inland edge of a broad flood plain that provides villagers with their largest expanse of agricultural land. Villagers refer to the northern and southern branches as Bitoi One and Bitoi Two respectively when speaking Tok Pisin, but in Kala the northern channel is known as Aleta and the southern channel as Daunewa. Both branches have changed their course significantly over the past few decades, and although Aleta now carries a significantly larger volume of water than Daunewa, this was not always the case.

The Tabale River descends behind the village, near the middle of Kamu Yali territory, and meanders through an extensive sago swamp before entering Nasau Bay. The Alewili River is located $10 \mathrm{~km}$ further south, well away from the main village and the main gardening areas, and is used mainly as a fishing camp. It descends much more abruptly into the sea than do the northern rivers, over steeper and rockier ground with less agricultural potential. Chromite deposits have been discovered at the mouth of the Alewili, and some families, in anticipation of future mining activities, have begun to plant crops and occupy the site more regularly in order to assert their claims as primary landowners in the area. Chromite deposits have also been discovered at the mouth of the Saia River, which lies a further $10 \mathrm{~km}$ south and serves as an informal boundary between the territories of Kamu Yali and Buso, another Kala village. In the account that follows, I describe the four main rivers of Kamu Yali in the order that I came to know them, beginning with the Tabale.

\section{The Tabale River}

My decision to conduct doctoral research in Kamu Yali came about as the result of information provided to me by VDT and the permission granted to me by the Kamiali Conservation Project Committee (KCPC), a village committee created to work with VDT on sustainable development projects in the village. One project involved the construction of a training centre and village guesthouse, and VDT arranged for me to stay in the guesthouse during my year in the village. The guesthouse is located in a secluded spot at the southern end of the main village, and is separated from the village proper by the Tabale River. As long as I was willing to get wet, I could easily wade across the river mouth where sand bars were constantly forming and reforming and the water was rarely more than 
waist high. Otherwise, if I wished to stay dry, I could approach one of the houses beside the river and ask to be ferried across in an outrigger canoe (see Figure 9.3). This was not always convenient, however, and local dogs could become quite aggressive if I approached an unoccupied home on my own. I was also cautioned never to wade across the river at night when crocodiles would occasionally frequent the river mouth. The Tabale River thus restricted my ability to spend time in the village observing daily activities and getting to know people other than those who came to visit me at the guesthouse.

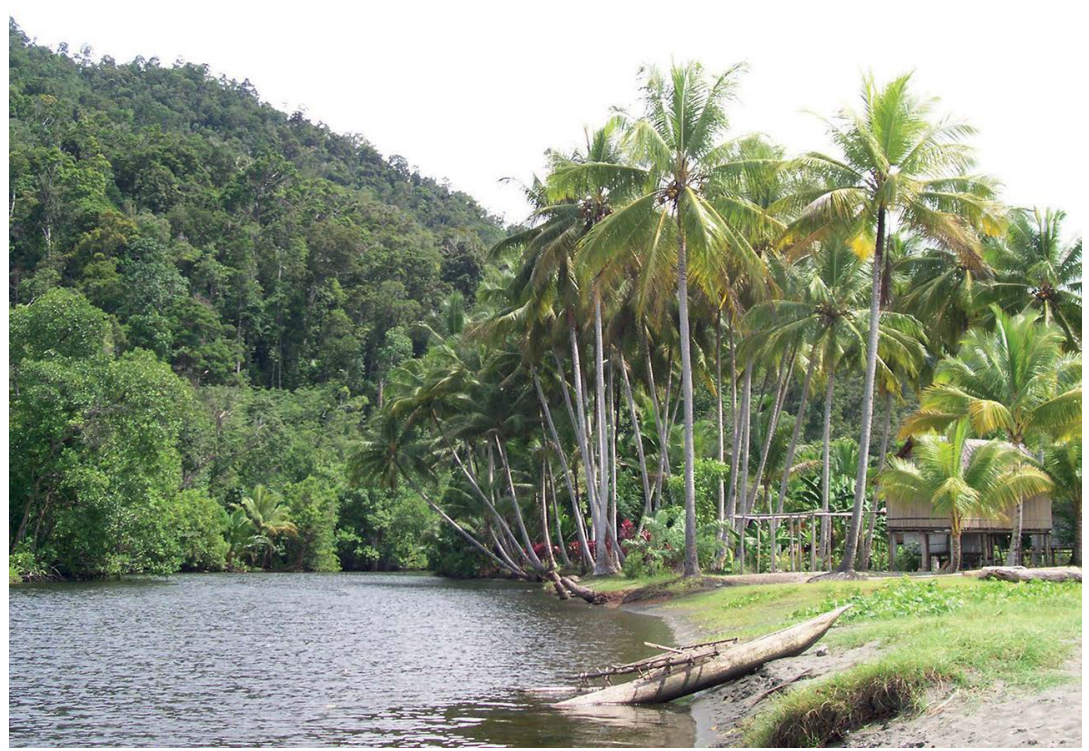

Figure 9.3 Ferry canoe at the mouth of the Tabale River.

Source: Photo by the author.

The Tabale has a very different character at different locations along its course. Several kilometres upstream from the village, at higher elevations, the riverbed is rocky and the water is clear and cool, but after completing its abrupt descent from Batatalã, it reaches a lowland shelf fronting Nasau Bay and meanders for $2 \mathrm{~km}$ through a dense mud-bottomed swamp. By the time it reaches the sea, most of the sediment has settled out, and the water is mostly clear where it courses over the sandbars at the river's mouth. At one point in its meanderings, it passes very close to the northern end of the village and, despite the murky quality of the water, 
this is where many villagers formerly came to bathe, wash their dishes and clothes, and fetch water for home use. These practices came to an end during my first few weeks in the village in 1998 when a new piped water system was completed with the assistance of VDT. The new gravity-fed water system brings water to a series of standpipes installed throughout the village, one for about every eight houses. Village women especially appreciate the convenience of the standpipes since they formerly had to make at least two trips to the river each day to fetch water, an especially onerous chore for those who live a kilometre or more away from the river. This piped water does not come from the Tabale River itself but from a smaller, cleaner tributary that joins the Tabale near its mouth.

The current village site extends along the shoreline for a distance of nearly $2 \mathrm{~km}$. Originally it was composed of a series of separate hamlets, each occupied by a distinct kin group, but most hamlets are now joined to form one continuous village, and the residential boundaries of kinship groups have grown less distinct. The upper or northern end of the village is still referred to as Bik Ples ('Big Place' in Tok Pisin) because of its denser population and its historic status as the main village site. Bik Ples is still occupied predominantly by members of the Gala moiety; before the piped water system was constructed, the Gala used the northern meander of the river as their main source of fresh water. Most members of the other moiety, the Aleme, who were scattered among several smaller hamlets lying south of Bik Ples, would go to a spot at the southern end of the village near the mouth of the Tabale River. The original water use pattern thus emphasised the separateness of the two moieties and provided a daily opportunity for reaffirmation of that separateness through the gatherings at two distinct sites at the beginning and end of each day. The piped water system has thus become one of several factors contributing to an ongoing reconfiguration of kin group identities and social networks. ${ }^{5}$ Moieties perform far fewer functions in the village today than in the recent past and are cross-cut by many new institutional forms, such as school, church and development committees.

5 See Hviding (this volume) on the cultural significance of a piped water system in the Solomon Islands. 
Despite ongoing changes to kin group identities, the Tabale River continues to hold deep historical significance for the Aleme moiety and for one of its most senior clans, ${ }^{6}$ which is also known by the name Aleme. Alternatively, both the moiety and its senior clan are referred to as Tabaleli, emphasising their historical relationship to the river. The Kala suffix $l i$ is a plural marker that is added to kinship terms such as Tabale in order to designate the entire group or clan. The name Aleme appears to be more recent than Tabaleli, for both the senior clan and the moiety, and was given to them by the Gala. A well-known story told by both Gala and Tabaleli individuals concerns the historical relationship of the two groups during a formative period in their history. Gala history is linked to the Bitoi River, and their original village sites were located either beside one of the two arms of the river or on a small island (Lababia) near the mouth of the southern channel of the river. The ancestors of the Tabaleli, on the other hand, lived near the mouth of the Tabale River. Whereas the Gala were primarily growers of taro, the Tabaleli were mainly dependent on sago and fish. The Gala jokingly referred to the Tabaleli as 'Aleme Aleme', because the Kala word me means 'and' while the word ale means 'water', so the literal meaning of the name is 'and water and water'. The name Aleme thus came to take on the meaning of 'people who go always to water', whether to fish along the fringing reef or to gather sago from the swamp alongside the river.

6 I use the English term 'clan' to refer to the named kinship groups that collectively make up each moiety in deference to the practice of Kamu Yali villagers when speaking or writing in English. English usage follows Tok Pisin usage in which klan ('clans') are distinguished from meja klan ('major clans'). I use the term 'moiety' rather than 'major clan' because, in anthropological terminology, the two larger groups function as moieties but do not constitute unilineal descent groups. The groups villagers refer to as 'clans' are best understood as cognatic rather than unilineal descent groups, and for that reason I have referred to them as 'ramages' in a previous publication (Wagner 2007: 30). Kala villagers use the suffix $l i$ to designate all kin groups-whether moieties, clans or smaller groups. There are no simple terms to distinguish groups of different size or status from one another; such distinctions can be made in Kala but require lengthy explanations. Kamu Yali thus represents an example of what McKellin (1991) has referred to as 'the pidginization of kinship terminology', reflecting a series of changes that have occurred since the colonial era and that now obscure the nature of pre-colonial kinship practices. The cognatic structure of Kamu Yali helps to explain another important feature of their kinship system, which is the ability to claim multiple clan affiliations and to switch one's primary affiliation if one so chooses. Burton (1996) has described a similar pattern among the neighbouring Biangai. Some Kamu Yali parents assign each of their children to one of their own parents' clans, so that a group of siblings can be distributed among as many as four different clans. 


\section{The Bitoi River}

Since my primary research goal in Kamu Yali in 1998-99 was to understand the ways in which villagers managed key resources, such as agricultural land, fisheries and forests, I began by trying to understand the rules of the land tenure system as it applied to agricultural land. The research proposal I sent to the village before my arrival included a request to map the distribution of agricultural land by landowning group, which was approved by a village committee. It did not take long to find out, however, that land boundaries were highly contested and that competing groups within the village were interested in supporting their claims through my mapping project. I therefore dispensed with the idea of mapping the lands of named groups in favour of a household-level study. Over a period of a few months, I was able to visit the swidden gardens of 26 households, interview male and female heads of household about their history of use of specific garden plots, survey the size of each of their gardens, and plot garden locations using GPS equipment. Families explained to me in Tok Pisin that each plot of land had a papa or mama bilong graun, who is the person considered to be the custodian of the ground by virtue of his or her senior position within an extended family or larger landowning group. This research approach revealed that most garden land was under the immediate control of relatively small, extended family groups that had flexible and somewhat unpredictable relationships with the named kinship groups in the village. Everyone agreed that the named groups held underlying rights to specific garden areas, but many areas were subject to competing claims, and some areas were claimed to be pablik graun ('public ground') for all to use. Most confusing for me, in the initial stages of research, was the lack of a clear relationship between the clan affiliation of the household head and the clan affiliation of the papa or mama bilong graun of each garden plot the family was using. Families had access to land through both matrilineal and patrilineal lines of succession and through all four grandparents of the male and female heads of household. Access to land was determined less by the type of kinship tie than by the personal relationship of the person using the land to the custodian of the land-a relationship that had to be constructed through the regular sharing of labour and other forms of gift giving and mutual support.

Despite the fluidity and complexity of the land tenure system, one fact became readily apparent to me during the first few weeks of my agricultural study. The vast majority of gardens were located beside rivers: 65 per cent 
of the total area under cultivation was located in the Bitoi delta (Wagner 2002; Bein et al. 2007) and 30 per cent was located beside the Tabale River near the village. Most other gardens were located on Lababia Island (Wagner 2002). The Bitoi delta is highly valued as agricultural land for a number of reasons. Soils are regularly enriched by the siltation carried by occasional floods; fallow periods are shorter than in other gardened areas because of high fertility and the trees that grow during fallow periods are therefore smaller and easier to clear away in preparation for planting; and land is flat and therefore easier to clear, plant, weed and harvest. Close proximity to the river also provides people with ready access to drinking water during the day and access to water for bathing and washing produce, especially sweet potatoes, before beginning the long trek home at the end of the day. On some occasions, families whose gardens were located furthest upriver would transport food by outrigger canoe to the mouth of the river, thus saving themselves, and especially the women who do most of the food carrying, a great deal of hard labour. My mapping of garden locations throughout the delta also made it clear that gardens clustered in certain areas, confirming what many people had already told me-that they liked to locate their gardens close to those of relatives and friends in order to maximise socialisation time and the sharing of labour.

In June 2000, nine months after I completed my doctoral research, the Bitoi delta flooded to such an extent that virtually all gardens were destroyed. Minor flooding had occurred in April 1998, four months before my arrival, and I was aware that many households had not yet entirely recovered from their losses by the time of my arrival. When planted crops are flooded they mostly rot and die, and it is not possible to replant in that area for another four to six months. Since it also takes four to six months for staple crops like sweet potatoes to mature after they are planted, and still longer for taro, a flood can significantly reduce household food production for as long as 12 months. Although minor floods cause significant hardship, villagers have many strategies for dealing with temporary food shortages: they typically plant several gardens in different locations so that if one floods another will still be productive; they harvest more wild food crops, especially sago, to make up for shortages of sweet potato and taro; and they rely on relatives whose gardens were not damaged and to whom they provided similar help in the past. Villagers I spoke to in 2002, when I next returned to the village, told me that the flood of 2000 was beyond the experience of any living member of their community. Neither the villagers nor the scientists who worked on occasion for VDT were able 
to offer a definitive explanation for why flooding had been so severe in that particular year. Perhaps it was a combination of upstream logging, climate change, heavier than usual rains and more intensive farming of the delta itself that causes destabilisation of river beds due to the depletion of secondary forest along the banks. Significant minor flooding occurred twice more in the 2000s, a significant departure from the once every five to 10 -year flood events that villagers reported experiencing over the previous several decades. The river thus brings significant benefits but also risks. I was not able to quantify the impact of this series of floods on gardening practices, but the anecdotal evidence I gathered suggests that the delta remained the site of intensive gardening activities throughout this decade despite these regular setbacks.

Two senior kinship groups in the village, the Amboli and Duweli, are recognised as the dominant landholding groups in the Bitoi delta (see Figure 9.2), with claims that were established well before the colonial period that began in the late 1800s. Both belong to the Gala moiety and both have distinct histories that link them to specific regions within the delta and to one of the two arms of the river. Amboli identity is closely tied to the cultivation of taro in areas near the Aleta, the northern branch of the river. Taro cultivation had virtually ceased by 1998 due to the spread of taro beetle to this region several decades previously, and discussions of taro growing at that time evoked particularly nostalgic memories of a time when taro, not sweet potato, was the dominant and most highly valued food crop. Once a highly effective beetle insecticide was made available, clan members quickly returned to taro as a preferred crop, and when I visited the village in 2013 it was abundant once again.

Yaling Michael, ${ }^{7}$ an especially knowledgeable member of Amboli, recounted stories to me in 1999 concerning the history of movement of his ancestors from various locations near or along the Aleta River, beginning with their occupation of a village site located on a hilltop called Mundiodo, about $2 \mathrm{~km}$ upstream from the mouth of the river. He could trace his own ancestry back eight generations, and stated that the first occupation of Mundiodo occurred seven generations ago. The following account of this occupation comes from a story Michael copied word

7 All personal names appearing in this chapter are used with the knowledge and consent of the individuals involved. 
for word from a book written by his father in Tok Pisin. The full story provides a partial explanation for the origin of the Balekatu, the Amboli sub-group to which he belongs:

Long ago, during the time of our ancestors, all the Amboli lived near Aleta on top of a little mountain called Mundiodo. They built a men's house for themselves and they called this Lumi Ambo. ${ }^{8}$ They carved all kinds of images on the house posts. After some generations our ancestors left Mt Mundiodo, beside Aleta, and they built a new men's house called Lumi Ambo on Lababia Island. Later on they moved again, building their men's house in a bay [near Aleta] called Balekatu.

The movement from Mundiodo to Lababia Island occurred as a result of a breakdown of the normally friendly relations between the Kala and a neighbouring inland group, the Biangai, who today live in several villages located near the town of Wau. After the Kala moved to Lababia Island, however, another neighbouring group, the Kaiwa, began to move into the Aleta area, giving rise to another series of violent skirmishes and an historic enmity that continues to this day. The performances of a village theatre group in 1998 emphasised the fact that, historically, men would accompany their wives in armed groups when travelling to gardens in the delta because of the ever-present possibility of Kaiwa attacks (Wagner 2002). The history of conflict between the two groups appeared to be drawing to a close by 1998, when I was first in the village, but erupted again in 2008 and dramatically shifted gardening practices for both Kamu Yali and Salus, a Kaiwa community located just north of Aleta. Many people from both communities were planting gardens in the delta in 1998, but the Kaiwa mainly planted on sites located on the northern side of Aleta or sites several kilometres inland from the mouth of the river. Once beyond $10 \mathrm{~km}$ from the river mouth, the delta gives way to higher ground, as one then enters the historic 'bush' territory of the Kaiwa. According to the Kala, the Kaiwa historically occupied inland forested areas, but after World War II, an Australian kiap (district official) moved a few Kaiwa communities down into shoreline villages in order to make it easier to reach them and provide services. According to Kamu Yali spokespeople, a Kala tultul (an appointed assistant to the kiap) gave permission to one inland Kaiwa community to move to a shoreline location just north of Aleta, and their descendants today live in the community of Salus, which

8 While 'clans' (klan) are designated in the Kala language by adding the suffix $l i$ to the group's core name, as with Amboli, Duweli and Aneli, men's houses are designated by placing the word lumi before the name, as with Lumi Ambo, Lumi Duwe or Lumi Ane. 
is located slightly north of their first village site. The residents of Salus tell a somewhat different version of this story, of course, and conflicts sometimes occur. For instance, a few Kala men told me stories of times when they had cut down trees planted in their Bitoi gardens by the Kaiwa in order to prevent the latter from establishing permanent claims to those areas. They had also destroyed small dams on the Aleta that Kaiwa men had built to create fish habitat.

Between 1950, when the village of Salus came into being, and 1998, when I arrived, there had been only one instance of large-scale violence between the two communities. Village men in Kamu Yali frequently told me stories of that fight, humorously pointing out men in the village who were now quite elderly, but who had been sent to jail for one month as punishment by the Australian colonial authorities. Apparently, men from Kamu Yali and Salus had confronted one another in force on a beach just north of the mouth of the Aleta. Many individuals had been injured but no one had been killed, and few of the combatants on either side had carried lethal weapons such as bush knives, spears or guns. Several Kala men reported to me in 1997 that they had Kaiwa 'trading partners' in Salus, and there were a few other examples of peaceful ties between the two communities. There was a decided lack of intermarriage, however, and a strong sense in Kamu Yali that such ties should not occur because of the simmering land dispute. It was not entirely unexpected, then, that hostilities broke out again in 2008 following a series of disputes in the gardening areas. The intensity of what happened in 2008 was shocking and unexpected, however, to people throughout the region and to most Kamu Yali and Salus villagers themselves. According to the accounts I heard, a gang of young Salus men, one of whom carried a gun and all of whom used drugs and were involved in the drug trade, had begun to threaten and harass Kamu Yali men and women in their gardens. This behaviour was reported to the police, who tried but failed to arrest gang members. The police then suggested to several Kamu Yali men that they should take matters into their own hands and, as reported in a national newspaper (Anon. 2008a, 2008b) and confirmed for me later by villagers, they burned the entire village of Salus to the ground. Two Salus men were killed during the conflict, but, despite a prolonged police investigation, no one was ever charged for the deaths. Various attempts were made over a period of several years to deal with the issue through compensation payments, and these efforts at reconciliation eventually restored peace but have not led to a firm agreement over land rights. Salus residents have returned and rebuilt their community with Kamu Yali consent. 
The Duweli are the other Gala clan with deep historic ties to the Bitoi area, but in their case the ties are to the southern branch of the river, the Daunewa (see Figure 9.4). The Duweli also cultivate taro but were more specifically known for their expertise in hunting pigs. According to the Duweli headmen whom I was able to interview as a group, pig hunting was then a collective enterprise involving the use of large nets. Today, by contrast, men hunt pigs individually with five or six dogs and a spear. Knowledge of the former Duweli pig-hunting practices is mostly lost today, but according to Duweli headmen, specialisations such as pig hunting were essential to the ways in which different Kala kin groups constructed their relationships to one another, each having special knowledge that would inform the ways in which food was procured and exchanged during the ceremonial events, such as marriages, that brought the groups together as a single community. Each group formerly maintained its own small village, centred on a men's house, which would be surrounded by the smaller houses occupied by wives and children.

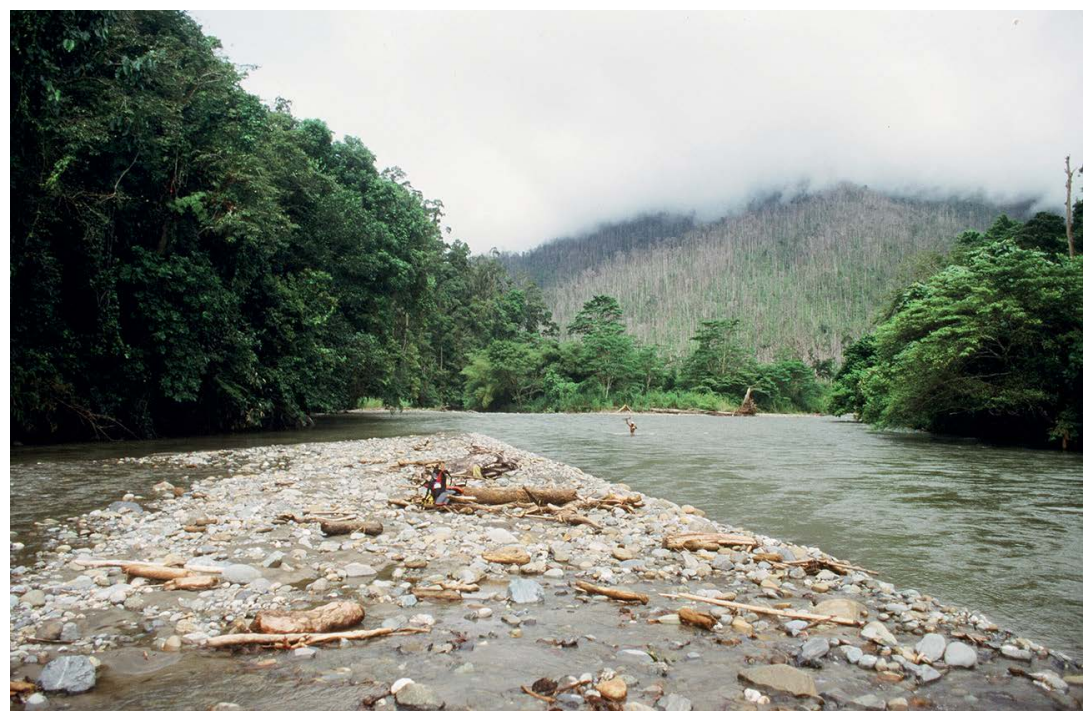

Figure 9.4 Fording the Bitoi River where it divides into Aleta and Daunawe branches.

Note: The small hill in the background burned during a dry spell in 1997, the year of an El Niño episode.

Source: Photo by the author.

Accounts by Gala headmen of the origins and histories of their various clans suggest that they maintained a clear sense of alliance and solidarity amongst themselves that was less fully shared with the Aleme whose village 
site was located near the mouth of the Tabale River. However, although the early histories and subsistence strategies of Gala and Aleme were significantly different, those differences also appear to have facilitated well-established, long-term reciprocal relations involving the sharing and exchange of foods, resources and marriage partners. They were also firm allies against the Kaiwa.

\section{The Alewili}

The Alewili River is very different from the Tabale and Bitoi by virtue of its more rapid descent from the mountains. There is a large swamp on the northern side of the river mouth but no flood plain to support agriculture on the scale that is practised in the Bitoi delta, and far less sago than along the Tabale. Gardening is possible on the higher ground surrounding the swamp and upstream along the river for a distance of about half a kilometre, after which the steep elevation and rugged terrain make gardening here less attractive than in other locations (see Figure 9.5). This helps explain why no village site has ever been located beside the Alewili, but other factors have also influenced this choice.

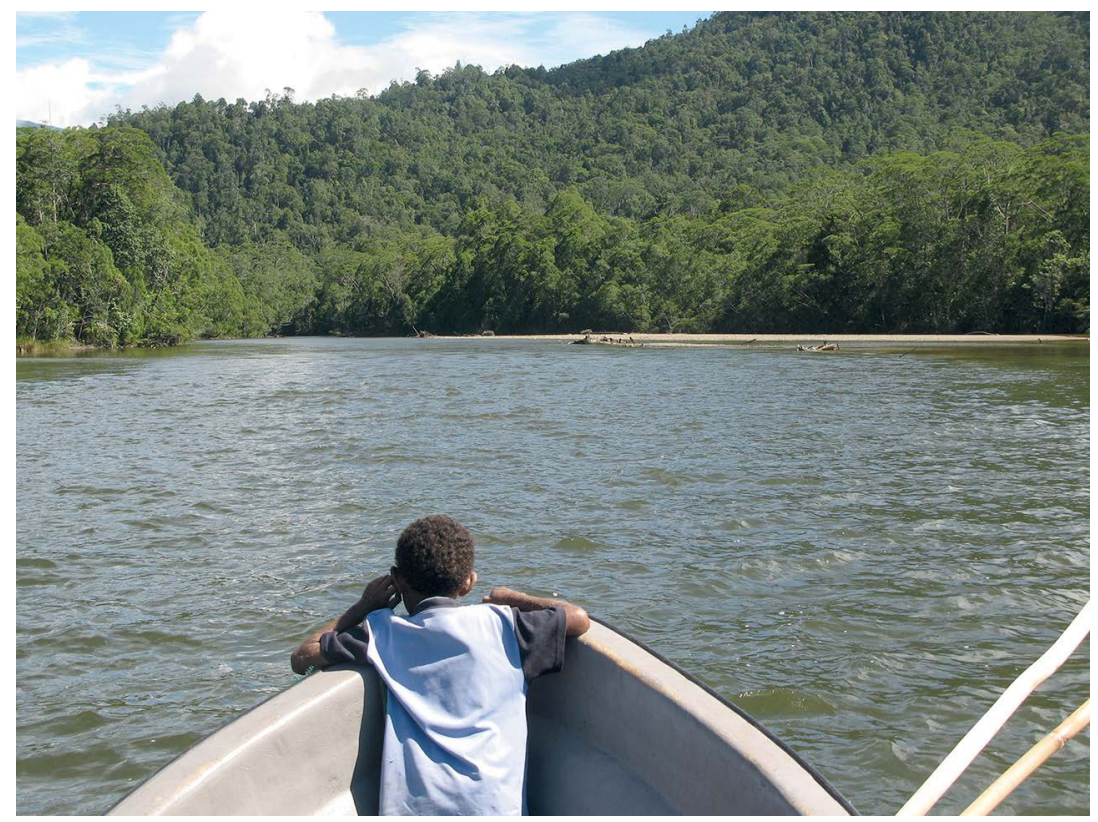

Figure 9.5 Heading upstream from the mouth of the Alewili River.

Source: Photo by the author. 
Gabu, one of the main leaders of the Tesiaolĩ, the clan most strongly associated with this area, explained to me in 2013 that the relationship of the Kala to this area is historically more recent than their relationship to the Bitoi and Tabale river areas. Kala people first began to frequent this area five generations ago, shortly before missionaries arrived in the area in the early 1900s. The main village site on Lababia Island had become overcrowded and families began to move to various locations near the Tabale River. Others explored areas further south and, according to Gabu, his ancestor Gõyu first began to live on Yawame Island (also known as German Island) at this time. Gõyu's father, Gosiligu, had already established a presence on the island, which is just offshore from the mouth of the Alewili, but Gõyu was the first to build a house there and plant a garden. Gõyu was very cautious in his first visits to the Alewili area on the mainland, which was previously unknown territory, both out of fear of attack by Kaiwa hunters and out of fear of the powerful spirits that resided there. He would spend short amounts of time there at first, until he felt confident that his presence was accepted, and then he began to regularly hunt and fish in the area, sleeping overnight on occasion, but still maintaining his house site on Yawame Island. This pattern continued for several years, but eventually, after missionaries arrived and built a church on Lababia Island, he converted and moved back to his previous home. His son Bolulu, however, continued to come to Yawame to garden and to the Alewili to fish and hunt. In this way, the family acquired and maintained the landownership rights they still hold over this area. Bolulu was Gabu's grandfather.

I acquired my first knowledge of this river through stories about groups of village men going there to fish in order to raise a bit of cash for the maintenance of school buildings, the church, medical aid post or for other collective village projects. Family groups would also go there to raise money for funeral expenses. In addition to its value as a fishing site, the Alewili was also one of the few places where a certain species of tree, necessary for the construction of outrigger canoes, could be found. My first visit to the Alewili occurred in 1999 during the time I was conducting a series of fishing trials with village men. Each man would take me by canoe to one or more of his favourite fishing spots where we would each fish, and I would record the size, number and species of fish caught and jot down accounts of fishing lore and sea tenure practices. Preferred fishing spots were usually located along the edges of fringing reef about half a kilometre from shore, and the Alewili was a preferred area 
for many. Fishing spots closer to the village tended to be less productive or more fished out, and most men did not like to go much further than Alewili on a one-day trip since it took a couple of hours of steady rowing to get there and a couple more to come back.

I was fortunate on one of my trips to be able to go with Bing Katu, then headman of the Aleme moiety. During the trip, he explained the 'rules' of sea tenure to me as they applied to fishing spots and the mouths of rivers. When he was a young man, he stated, people paid much closer attention to traditional rules, whereas now everyone in the village felt free to fish anywhere in Kamu Yali territory. He himself continued to fish only in Aleme territory, which extended from the Tabale River south to the Saia. A few fishing spots within this territory would once have been recognised as belonging to one family group, or one clan, or simply as the favourite fishing sites of one or two men-preferences that were mostly respected by other men. The Aleme headman explained to me that the leaders of specific kin groups were considered the wasman ('watchmen') or custodians of river mouths, and that these rights were still active despite the recent movement towards a village fishing commons as opposed to family or clan commons. He identified members of the Tesiaolĩ clan as custodians of the mouth of the Alewili and surrounding territory, but without mentioning their clan membership. In fact, the Tesiaolĩ had not even been mentioned when I first began gathering the names of village clans. Individuals who I subsequently came to understand were Tesiaolĩ had identified themselves to me as Mambali, a minor clan with overlapping membership, but an entirely different history. The emergence of Tesiaolĩ and seeming disappearance of Mambali during the 19992013 period appears almost entirely attributable to villagers' responses to mining exploration.

The Alewili today is still regarded as the home of dangerous and powerful spirits, and villagers do not come here unless they are Tesiaolĩ or are accompanied by someone who is. My first experience of the area, in 1999, provided me with a striking confirmation of the special relationship between the Alewili and the Tesiaolĩ. Towards the end of my doctoral research year, Yaling Michael invited me to go there on an overnight 'picnic', something I rarely experienced in the village, and I happily agreed. Since Michael has no clan rights in the area he invited Yaga, a Tesiaolĩ member, to come with us. Michael maintained a close relationship with Yaga by virtue of the fact that they were married to sisters and often worked together in their gardens. This first trip was especially memorable because of heavy rains 
that fell in the night and threatened to wash away our small campsite, where I had pitched my tent and where the others had constructed small, temporary sleeping huts for themselves. In the morning, I was told that Yaga had arisen in the night and, noticing that the river was beginning to overflow its banks, had quickly cut down several nearby saplings and created a row of stakes between our camp and the rising water. He then performed a ritual in which he asked the water to come no further than the line of stakes. When I was told this story in the morning, everyone pointed out to me, with a good deal of satisfaction but also amusement, that the river had risen exactly to the line of stakes and then retreated, as demonstrated by the wetness of the sand on the river side of the stakes.

This was one of the very few occasions during my year-long stay in the village in 1998-99 when villagers openly acknowledged or demonstrated their continuing use of Indigenous, non-Christian, ritual knowledge. My first such experience had occurred when I went on an overnight trip into the mountains with three hunters. These hunters were all well-known to me, and all had described hunting practices to me before, but once in the bush, sitting at night around a fire, they began to describe some of the ways in which their hunting activities were guided by the kinds of dreams and magical knowledge so often described in the PNG literature on this topic. Previous attempts to question villagers directly on the use of nonChristian ritual, in gardens or when fishing or hunting, had always met with denials that any such practices existed, though, on some occasions, stories were told of such practices and regret was expressed at the loss of knowledge that had occurred since adopting Christian practices. The ritual line of stakes in the ground at Alewili thus reinforced my sense that while Christianity was clearly the dominant religion in the village, Indigenous practices continued to hold sway in the bush. Villagers have abandoned and forgotten many-perhaps most-Indigenous practices, but under certain circumstances they are remembered and revived under the guidance of those who did not forget.

Mineral analyses conducted by the Katana mining company in 2012 confirmed that the area surrounding the mouth of the Alewili River contains a rich chromite deposit. The company also confirmed the findings of previous exploration companies: that more extensive but less rich deposits were present at the mouth of the Saia River. As villagers began to mobilise in response to the Katana initiative, the underlying logic of their land tenure system was revealed with singular clarity. Those who hold the strongest landownership claims to Alewili are the descendants 
of Gõyu. At the time when he moved south to Yawame Island and to the mouth of the Alewili River, Gõyu belonged to the Balekatu, a Gala clan closely related to the Amboli, but his claim to the Alewili does not extend to the Balekatu clan as a whole; rather, it remains with him and his own immediate descendants. His personal claim to Alewili is based on the fact that he was the first to fish, hunt and garden in the areaactivities that all required him to cultivate a personal relationship with the spirits of the place and gain their acceptance. This appears to be the most fundamental of all the underlying principles that inform landownership practices at Kamu Yali. As a primary principle, it generates almost endless opportunities for the collapse and re-configuration of landowning groups in response to the changing values of particular resources. Now that the Alewili has acquired new value as a chromite mining site, all descendants of Gõyu, whether traced through male or female lines or both, have reason and opportunity to declare their primary affiliation as Tesiaolĩ. The size and status of Tesiaolĩ has thus expanded at the expense of other kin groups, most notably Mambali.

\section{The Saia}

According to Thomas Yawing, a leading member of the Ane clan, the main landowning group in the Saia area, an ancestor by the name of Kapalia moved south from Kamu Yali in the late 1800s, around the same time as Gõyu. He went first to Yawame Island, then to Lasanga Island near present-day Kui, as a result of an epidemic that struck Kamu Yali in the late 1800s. Like the Alewili, the Saia area at that time had a reputation as a place of dangerous spirits, but also as a place of abundant resources. The most dangerous spirits are said to inhabit a swampy area adjacent to the river itself. There are areas suitable for gardening but they are not extensive. Wild game, fish, turtles and wild sago are abundant, and also a particular species of pandanus tree valued for its fruit. The clan name, Ane, is, in fact, derived from the name of this particular tree.

According to Thomas and Hamm Giamsa, another member of Aneli, Kapalia and his sons gradually built a relationship with the spirit beings who occupied the region. Thomas and Hamm also related a story about how Kobõmbia, one of Kapalia's sons, led a group of Kala men in battle against a Kaiwa group that came to challenge their claim to this area. Their victory in battle thus consolidated their claim. Thomas and Hamm emphasised the reputation of Aneli at that time as powerful sorcerers who 
augmented their power by eating their fallen victims. They also stated that a collection of material items dating from around this time, such as knives, shell jewellery and other decorative materials, were collected and hidden in a secret location in the forest to preserve a record of their historic occupation of the area. This site remained intact until the close of World War II, when allied US and Australian forces used aerial bombardment when retaking this area from the occupying Japanese. No one has since been able to locate the site.

When I was first in Kamu Yali in 1998, I was told that a local court ruling in the 1970s had declared the Saia River to be the boundary between Kamu Yali and Buso, and that the entire area on the Kamu Yali side fell under the authority of the Aleme moiety. The court case arose in response to chromium exploration activities in the area by Conzinc Riotinto of Australia, the first company to conduct such studies. But Thomas and Hamm did not even mention this court case when they recounted Aneli history for me in 2013, and they did not indicate that the Aleme were senior holders of rights to the Saia area. This did not entirely surprise me, since it was consistent with other changes in the ways villagers were describing kin structures in 2013 by comparison to 1998 . The local land court had apparently ruled that the Saia River was the boundary between the two villages on the basis of an argument put forward by the headmen of the Aleme moiety at Kamu Yali. The headmen argued that the rights of the Aneli, since they are an Aleme clan, are subject to the overarching authority of the moiety, or 'major clan', and that the Saia therefore falls under Aleme control. The land court magistrate who ruled on the case accepted this argument, but because Aneli spokespeople from Buso disputed the Aleme claim, he felt compelled to establish village boundaries as well. Unfortunately, he did so in a way that entirely confounds the historic relationship of the Aneli in Buso to the Aneli in Kamu Yali. The Aneli have always been the largest clan at Buso, though other clans such as the Duweli and Amboli are also present. But, unlike the situation at Kamu Yali, where everyone belongs to one of two moieties, either Gala or Aleme, everyone at Buso belongs to a single group known as Bwaboli, a name that derives from Bwabo, the place on Lasanga Island where Kapalia and his family lived before establishing themselves at Saia and founding the community of Buso. The Aneli at Buso therefore do not consider themselves subject to the higher authority of the Aleme moiety at Kamu Yali. 
This is only one of several instances in which the prominence of the Aleme moiety has diminished over the past decade in respect to land rights, but rather than overwhelm readers with more details about the fluid nature of Kala kinship structures, I wish to return to the question of memory and forgetting in respect to rivers and the passage of time. The individual who first told me about the 1970s court case also showed me a two-page fragment of a typed copy of a court decision that he had obtained from his father, one of the Aleme leaders at the time, long ago deceased. When I subsequently tried to locate a copy of the full, written court decision from the provincial Department of Lands, I was told, after repeated visits and an exhaustive search, that they had no such record in their possession. His short fragment, yellowed with time and edged with mildew, about to pass out of collective memory altogether, thus provides an unexpected metaphor for the mutability of human actions as they erode with the passage of time and the capacity of each generation to select and discard the fragments that hold most meaning in relation to contemporary events.

As the court case disappears from memory, other bodies of knowledge about the Saia are recovered and reassembled, vital once again despite their suppression by missionaries over 100 years ago. Spokespeople and knowledge keepers for both the Aneli and Tesiaolĩ clans now find themselves evaluating the value of that knowledge by comparison to the economic value of chromite mining. Those I have spoken to express deeply conflicted emotions when asked whether they will agree to allow mining at the mouths of their rivers. Thomas Yawing, for instance, states that he is opposed to mining because of his worries about environmental damage, and because mining activities will obliterate the relationships he has nurtured with the ancestor spirits of the Saia area during his lifetime. But, according to Thomas, the general consensus among Aneli members may be in favour of mining. Hamm, on the other hand, after seeing half a dozen mining exploration companies come and go since the late 1960s, does not believe that actual mining will ever occur, and therefore sees no reason to take a side one way or the other.

\section{Conclusion}

Rivers shape and transform the land over which they flow and the seas into which they empty; they sustain an endless number of unique riparian habitats and the lives of the many species that thrive in their immediate vicinity. Human beings are one such species, and coastal people, no less 
than inland people, are almost always found near rivers, creeks or other easily accessible sources of fresh water. The human need for fresh water continues to dominate and predict settlement patterns everywhere in the world and, despite our hydro-engineering prowess, desert cities like Las Vegas and Phoenix in the United States, cities that long ago outgrew their local water supplies, are still the exception rather than the rule. We can, usually at great cost to ourselves as well as other species, change the path of flowing water, capture it in concrete channels, put it to work as an agent of industrial development-but these actions emphasise rather than diminish the power of water to shape social lives.

The Kala people cannot unambiguously be categorized as a 'river people', but they can be described as a 'river mouth people', and this is true not only of Kamu Yali but of all six Kala villages, all located on the beaches of the Solomon Sea near the mouths of rivers. Their strong dependence on rivers, despite their close proximity to the sea, may be an outcome of the lower productivity of their marine environment by comparison to the Marovo Lagoon described by Hviding (this volume). But as both Mondragón (this volume) and Hviding emphasise, river mouths are where fresh water and salt water meet, where land and sea intermingle, and as a consequence are unusually rich and diverse environments, equally potent in social, ecological and cosmological terms.

The social history of Kamu Yali is, in large measure, the outcome of its relationships with the four distinct rivers described in this chapter. Villagers' relations with non-Kala neighbours are structured around their willingness to go to war, if necessary, to defend their river adaptations. Intra-village relations are structured around the distinct practices and identities of the kin groups associated with each river, distinctions that arose historically by virtue of the fact that one river environment was more suitable for growing taro, another for harvesting sago, another for fishing, another for gathering the fruit of the pandanus palm. I have also demonstrated in this chapter how a new kin group, such as the Tesiaolĩ, can emerge from the actions of an individual or family group who, through a combination of need, opportunity, courage and desire, come to know a river for the first time or come to know it in a new way.

Like the Sepik River described by Silverman (this volume), Kamu Yali rivers have so far resisted the development aspirations of their human population. The Bitoi delta has not become a site for commercial agriculture largely because of the high cost of transporting produce by 
boat to regional or more distant markets. The Tabale River's swamps supply villagers with a ready supply of sago and are home to a growing population of crocodiles, but crocodile tours, though attempted, have never featured prominently in the modest ecotourism industry Kamu Yali has been able to sustain over the past decade and a half. Mining activities at the mouths of the Alewili and Saia rivers, however, now present villagers with a significant development opportunity. Chromite exploration at the mouths of these rivers has tantalised villagers since the 1960s with the possibility of royalty income and wage labour, but no mining has yet taken place. Unlike previous exploration companies, however, Katana has formally applied to the PNG Government for a mining licence, and in 2013 they conducted the impact assessment studies necessary to obtain such a licence. Today the Tesiaolĩ, Aneli and their near relatives are remembering and reconstructing largely forgotten bodies of knowledge concerning the special relationships of their ancestors Gõyu and Kapulia to the Alewili and Saia; they must do this in order to confirm their claims as landowners. At the same time, however, they are being asked to forget, to throwaway the practices through which their ancestors constructed their relationships with these rivers, to dismiss them as of less value than the financial rewards of mining and the dream of a 'modern' life.

In their own way, the rivers are also engaged in a complex process of memory and forgetting. The chromite deposits present at the mouth of the Alewili and Saia are alluvial deposits; their concentration at these sites is largely the outcome of the actions of the rivers over thousands of years. Chromium extraction, if it occurs, will entirely rearrange these formations, degrading both downstream riparian zones and the adjacent marine environments. But the rivers will continue to carry water nonetheless from Batatalã to the sea, will continue to arrange and rearrange the sediments at their mouths, forgetting each old arrangement as a new one emerges. Without losing sight of the mnemonic significance of rivers, as emphasised by Harrison (2004), I would like to conclude by also noting their mimetic significance. As Krause (2010), Edgeworth (2011, 2014), Féaux de la Croix (2011) and Strang (2014) propose, and as noted in the introduction to this volume, the flow of water provides a useful metaphor for both the passage of time and the fluidity of cultural forms as they respond over time to social and ecological actions and reactions. Harrison (2004: 141) evokes the mimetic as well as mnemonic qualities of rivers when he describes the broad, marshy plains of the meandering Sepik River as a 'forgetful landscape'. From this perspective, culture itself is very like 
a river, and cultural analysis gains traction through careful observation of river ecology and a willingness to treat rivers, as well as humans, as the subject of ethnographic enquiry.

\section{Acknowledgments}

Funding for the fieldwork that informs this paper was provided by the Social Sciences and Humanities Research Council of Canada, the International Development Research Centre of Canada, Okanagan University College, the University of British Columbia Okanagan, the University of British Columbia Hampton Foundation, the Firebird Foundation for Anthropological Research and the US National Science Foundation. I would like to thank all those who participated in the conference sessions that led to this publication and the Association for Social Anthropology in Oceania for sponsoring the sessions. I would also like to acknowledge the insightful and constructive comments of two anonymous reviewers. Finally, I would also like to express my deep gratitude to the many Kamu Yali residents who have shared their time, insights and hospitality with me over a period of two decades now, especially those whose knowledge and experience most directly informed this paper.

\section{References}

Anon., 2008a. 'Investigators Dig-Up Evidence.' Post-Courier, 18 January.

_ 2008b. 'Police Role in Fatal PNG Raids Denied.' Post-Courier, 21 January.

Barad, K., 2003. 'Posthumanist Performativity: Toward an Understanding of How Matter Comes to Matter.' Signs: Journal of Women in Culture and Society 28: 801-831. doi.org/10.1086/345321

Bein, F.L. (ed.), 1998. 'Kamiali Wildlife Management Area Bio-Diversity Inventory: A Report Prepared for Village Development Trust.' Lae: PNG University of Technology, Environmental Research and Management Centre.

Bein, F.L., J. Wagner and J. Wilson. 2007. 'Food Garden Carrying Capacity of the Bitoi River Delta for the Kamiali Wildlife Management Area.' Focus on Geography 50(2): 28-33. doi.org/10.1111/j.1949-8535.2007.tb00194.x 
Bennett, J., 2010. Vibrant Matter: A Political Ecology of Things. Durham (NC): Duke University Press.

Burton, J., 1996. 'Aspects of Biangi Society: The Solorik System.' Canberra: Pacific Social Mapping (Hidden Valley Project Working Paper 3).

Descola, P., 2013. Beyond Nature and Culture (transl. J. Lloyd). Chicago: University of Chicago Press.

Edgeworth, M., 2011. Fluid Pasts: Archaeology of Flow. London: Bloomsbury.

—_, 2014. 'On the Agency of Rivers.' Archaeological Dialogues 21: 157-159. doi.org/10.1017/S1380203814000166

Féaux de la Croix, J., 2011. 'Moving Metaphors We Live By: Water and Flow in the Social Sciences and around Hydroelectric Dams in Kyrgyzstan.' Central Asian Survey 30: 487-502. doi.org/10.1080/02634937.2011.614097

Harrison, S., 2004. 'Forgetful and Memorious Landscapes.' Social Anthropology 12: 135-151. doi.org/10.1017/S0964028204000436

Hodder, I., 2012. Entangled: An Archaeology of the Relationships between Humans and Things. New York: Wiley. doi.org/10.1002/9781118241912

Ingold, T., 2000. The Perception of the Environment: Essays on Livelihood, Dwelling and Skill. London: Routledge. doi.org/10.4324/9780203466025

Ingram, M., 2010. 'Fermentation, Rot, and Other Human-Microbial Performances.' In M. Goldman, P. Nadasdy and M. Turner (eds), Knowing Nature: Conversations at the Intersection of Political Ecology and Science Studies. Chicago: University of Chicago Press.

Krause, F., 2010. Thinking Like a River: An Anthropology of Water and its Uses along the Kemi River, Northern Finland. Aberdeen: University of Aberdeen (PhD thesis).

Latour, B., 2005. Reassembling the Social: An Introduction to Actor-Network Theory. Oxford: Oxford University Press.

Malafouris, L. and C. Renfrew, 2013. How Things Shape the Mind. Cambridge: MIT Press.

McKellin, W.H., 1991. 'Hegemony and the Language of Change: The Pidginization of Land Tenure among the Managalase of Papua New Guinea.' Ethnology 30: 313-324. doi.org/10.2307/3773687

Morton, T., 2013. Hyperobjects: Philosophy and Ecology after the End of the World. Minneapolis: University of Minnesota Press. 
Schreyer, C. and J. Wagner, 2013. 'Kala Bijatuwã: A Community-Driven Alphabet for the Kala Language.' In N. Ostler and M. Norris (eds), Endangered Languages Beyond Boundaries: Community Connections, Collaborative Approaches, and Cross-Disciplinary Research. Ottawa: University of Carleton Press.

Strang, V., 2014. 'Fluid Consistencies: Material Relationality in Human Engagements.' Archaeological Dialogues 21: 133-150. doi.org/10.1017/ S1380203814000130

Viveiros de Castro, E., 1998. 'Cosmological Deixis and Amerindian Perspectivism'. Journal of the Royal Anthropological Institute 4(3): 469-488.

Wagner, J., 1999. “"Blue Mountains Constantly Walking”: The Resignification of Nature and the Reconfiguration of the Commons in Rural Papua New Guinea.' Canberra: The Australian National University, Resource Management in Asia-Pacific Program (Working Paper 24).

— 2002. Commons in Transition: An Analysis of Social and Ecological Change in a Coastal Rainforest Environment in Rural Papua New Guinea. Montreal: McGill University (PhD thesis).

- 2005. 'The Politics of Accountability: An Institutional Analysis of the Conservation Movement in Papua New Guinea.' In P.J. Stewart and A. Strathern (eds), Anthropology and Consultancy: Issues and Debates. New York: Berghahn Books.

— 2007. 'Conservation as Development in Papua New Guinea: The View from Blue Mountain.' Human Organization 66: 28-37. doi.org/10.17730/ humo.66.1.q21q23v06t374204 
This text is taken from Island Rivers: Fresh Water and Place in Oceania, edited by John R. Wagner and Jerry K. Jacka, published 2018 by ANU Press, The Australian National University, Canberra, Australia.

doi.org/10.22459/IR.06.2018.09 